\title{
Information Assessment Model Based on Low-carbon Theory
}

\author{
Yiping Yang ${ }^{1}$, Hong Qiao ${ }^{2}$, Xianfa Zeng ${ }^{3}$ \\ Information College, Capital University of Economics and Business, Beijing, 100070, China \\ 1yyp6475@yahoo.com.cn, ²qhluck@gmail.com, 3xianfazeng@163.com
}

Keywords: Low-carbon, IT Assessment, Real Option, fuzzy Environment

\begin{abstract}
This paper integrates the fuzzy mathematics theory, finance theory, assessment theory and etc., using a variety of tools such as MATLAB, SPSS and Excel, under the consideration of the uncertainty and volatility of the IT investment and the diversification and intangibility of the IT profit, and builds the IT real options assessment model under the fuzzy environment. The expected investment costs and benefits are represented by fuzzy numbers, because the ambiguity of IT cost-benefit makes parameters of the model difficult to be accurately predicted. Based on the above study, taking into account of the low-carbon indicator, the paper optimizes the fuzzy real options model. Through using manufacturing enterprise samples, the IT real option values are calculated and detail analysis for the results are made. And by studying the relationship and mutual influence pattern between IT and low-carbon index, this paper provides theoretical guidance for the low-carbon IT development and enhances the construction of resource-saving society and low-carbon economy in China.
\end{abstract}

\section{Introduction}

In the era of knowledge-based economy, the high-tech industries are increasingly becoming the core driving force of economic development, and information technology (IT) has undergone a fundamental shift in the role of business, thus the focus of the enterprise information value assessment from a simple measure of financial indicators shifts to the enterprise whole value enhancement. In addition, as the increasing proportion of carbon emissions from the information area in the total emissions, the possession of information construction is not only related to the efficiency of enterprises, but also to carbon emissions in the production and business activities related to enterprise information. This paper aims to find an enterprise information construction assessment theoretical model, which is more comprehensive, objective and quantifiable to analyze the results of the investment in information technology.

The main purpose of this paper is looking for an enterprise information construction assessment theoretical model, which is more comprehensive and objective and gives full consideration to the uncertainty, volatility of IT investment and the diversity and intangibility of earning, and establish Real Option Valuation model for the analysis of the results of the investment in information technology in a fuzzy environment; at the same time taking into account the relationship of low-carbon and Information Technology, based on which to make improvement. Compared with traditional methods and previous research, the fuzzy real option model with consideration of low-carbon factor can analyze the commercial value of enterprise information and strategic significance more systematically and comprehensively.

First, this paper integrates the fuzzy mathematics theory, finance theory, assessment theory and etc., using a variety of tools such as MATLAB, SPSS and Excel, under the consideration of the uncertainty and volatility of the IT investment and the diversification and intangibility of the IT profit, and builds the IT real options assessment model under the fuzzy environment. The expected investment costs and benefits are represented by fuzzy numbers, because the ambiguity of IT cost-benefit makes parameters of the model difficult to be accurately predicted. Second, taking into account the low-carbon indicators from the perspective of enterprise information capability maturity model (EICMM) system, the paper optimizes the fuzzy real options model, which provides theoretical guidance and quantitative evaluation basis for the smooth development of enterprise 
information process. Third, using manufacturing enterprise samples, the IT real option values are calculated through the IT real options assessment model under the fuzzy environment and detail analysis for the results are made. Double dimensionless are done to make sure that the IT real option value in enterprises of different sizes are comparable, which makes it possible to measure the effectiveness of the performance of enterprise information according to the IT real options value comparison of sample enterprises. And by studying the relationship and mutual influence pattern between IT and low-carbon index, this paper provides theoretical guidance for the low-carbon IT development.

\section{IT Fuzzy real options model and analysis}

Based on previous studies basis, information technology assessment methods can be divided into financial indicators-based assessment methods, management of logistics based assessment methods, economics-based assessment methods and effectiveness conversion based assessment methods. However, the value of enterprise information technology investment projects depends largely on the option value of the project. The value of enterprise information investment cannot immediately reflect from the investment itself, but gradually reflected in the subsequent business activities. So the real option approach based on economic evaluation has strong applicability. However, most of the ROA methods stay in the concept stage. The model building or individual quantum calculations were only in a particular case of an enterprise application, and no sub-industry, systematic model were built. But they did not consider the cost fluctuations, the fuzzy environment IT assessment, and the low-carbon factors.

According to the special nature of information technology assessment, and for the most methods failed in the past to consider the fuzzy elements, non-monetary costs and investment flexibility, input and output factors, taking into different scales between the comparability of information on real options, build the enterprise information assessment model based on the multi-dimensional vectors. Black-Scholes model was initially established by Fischer Black and Myron Scholes (1973). The main idea is under the assumption of knowing the stock price distribution and ignoring transaction costs, and you can use the stock and a risk bond portfolio, and the option price is equivalent to cost of the dynamic replication. The call option pricing formula is as following:

$$
\left\{\begin{array}{l}
C=\operatorname{PsN}\left(d_{1}\right)-X e^{-r T} N\left(d_{2}\right) \\
d_{1}=\frac{\ln (P S / X)+\left(r+\frac{1}{2} \sigma^{2}\right) T}{\sigma \sqrt{T}}, d_{2}=d_{1}-\sigma \sqrt{T}
\end{array}\right.
$$

In the original formula, the various parameters can be expressed respectively:

$\mathrm{X}$ - option settlement price; $P s$ - the current market value of financial assets

$\mathrm{T}$ - the valid period of the option

$\mathrm{r}$ - continuously compounded risk-free interest rate

$\sigma$ - the annualized standard deviation

$\mathrm{N}($ ) - the cumulative normal distribution variable probability distribution function

\section{Fuzzy real options model optimization based on low-carbon concept}

Enterprise information construction process in the actual environment is in the incomplete information condition, and their pricing parameters are no accurate because of the estimated factor's ambiguity. However, the excessive pursuit of the input parameters will cause the output incorrect. From the view of fuzzy theory, the cost and benefits factors of enterprise information are fuzzy numbers. the information benefits can be represented as a trapezoidal fuzzy number $\mathrm{V}=\left[v_{1}, v_{2}\right.$, 
$\left.\alpha_{1}, \beta_{1}\right]$, which means it is mostly in the scope of $\left[v_{1}, v_{2}\right]$, and the up line is $\left(v_{2}+\beta_{1}\right)$, down line is $\left(v_{1}-\alpha_{1}\right)$, and it is the similar with the cost factor $\mathrm{I}=\left[i_{1}, i_{2}, \alpha_{2}, \beta_{2}\right]$. The information option can be represented as below:

$$
C=V e^{-r \Delta T} N\left(d_{1}\right)-I e^{-r \Delta T} N\left(d_{2}\right)
$$

The values of $V, I$ are uncertain, and can be represented by trapezoidal fuzzy numbers as mentioned above.

$$
\begin{aligned}
& V \in\left[V_{1}, V_{2}\right] .\left(V_{2}+\beta_{1}\right),\left(V_{1}-\alpha_{1}\right) \\
& \left\{\begin{array}{l}
d_{1}=\frac{\ln \left(\frac{V}{I}\right)+\left(r+\frac{1}{2} \sigma^{2}\right) \Delta T}{\sigma \Delta T} \\
d_{2}=\frac{\ln \left(\frac{V}{I}\right)+\left(r-\frac{1}{2} \sigma^{2}\right) \Delta T}{\sigma \Delta T}
\end{array}\right.
\end{aligned}
$$

EIOV (Enterprise Information project real Option Value ) represents the enterprise information real option value under fuzzy environment. T represents the valid period in year. $\sigma$ represents the annualized standard deviation of real option, which is the joint volatility of the cost and gain value of enterprise information project, in which the $\sigma 1$ is information technology earnings volatility, $\sigma 2$ is the volatility of the investment costs, $\mathrm{N}(\mathrm{d})$ is the normal distribution of the probability that the value is less than $\mathrm{d}$. $\mu$ is the options loss in the duration. The improved model by trapezoidal fuzzy numbers can be expressed as follows:

$$
\begin{aligned}
E I O V= & V e^{-\mu T} N\left(d_{1}\right)-I e^{-r T} N\left(d_{2}\right) \\
= & {\left[V_{1}, V_{2}, \alpha_{1}, \beta_{1}\right] e^{-\mu T} N\left(d_{1}\right)-\left[I_{1}, I_{2}, \alpha_{2}, \beta_{2}\right] e^{-r T} N\left(d_{2}\right) } \\
= & \left\{V_{1} e^{-\mu T} N\left(d_{1}\right)-I_{2} e^{-r T} N\left(d_{2}\right),\right. \\
& V_{2} e^{-\mu T} N\left(d_{1}\right)-I_{1} e^{-r T} N\left(d_{2}\right), \\
& \alpha_{1} e^{-\mu T} N\left(d_{1}\right)+\beta_{2} e^{-r T} N\left(d_{2}\right), \\
& \left.\beta_{1} e^{-\mu T} N\left(d_{1}\right)+\alpha_{2} e^{-r T} N\left(d_{2}\right)\right\}
\end{aligned}
$$

And,

$$
\left\{\begin{array}{c}
d_{1}=\frac{\ln \frac{E(V)}{E(I)}+\left(r+\frac{\sigma^{2}}{2}\right) T}{\sigma \sqrt{T}} \\
d_{2}=\frac{\ln \frac{E(V)}{E(I)}+\left(r-\frac{1}{2} \sigma^{2}\right) \Delta T}{\sigma \sqrt{T}}
\end{array}\right.
$$

Through research and analysis, IT department management costs factor, the cost of information technology hardware and software factors, information technology equipment maintenance cost factor, information technology strategy planning and implementation of the index factor, the index factor of the level of enterprise information and business information strategy to support the index factor, which are totally six factors to be used in the cost elements analysis of the manufacturing enterprise information. And the benefits factors include: the growth of the turnover of enterprises, 
enterprise gross profit growth, annual management fees accounted for to reduce the proportion of the value of the stock of goods reduce, enhance customer satisfaction, shorter delivery time. In other words, $\mathrm{V}$ and I is trapezoidal multi-dimensional vectors constituted by different factors. And they can be expressed as the following forms:

$$
\begin{gathered}
V=\left(V_{1}, V_{2}, \ldots, V_{n}\right) \\
I=\left(I_{1}, I_{2}, \ldots, I_{m}\right)
\end{gathered}
$$

For $V_{i}$ and $I_{j}: I_{j}=\left[I_{j_{1}}, I_{j_{2}}, \alpha_{j_{2}}, \beta_{j_{2}}\right] ; V_{i}=\left[V_{i_{1}}, V_{i_{2}}, \alpha_{i_{1}}, \beta_{i_{1}}\right]$

Under the consideration that $\mathrm{V}$ and $\mathrm{I}$ are multidimensional attributes, enterprise information real options multi enterprise information option value MEIOV (Multi-EIOV) can be expressed as:

$$
\begin{aligned}
M E I O V & =V e^{-\mu T} N\left(d_{1}\right)-I e^{-r T} N\left(d_{2}\right) \\
& =\left[V_{1}, V_{2}, \alpha_{1}, \beta_{1}\right] e^{-\mu T} N\left(d_{1}\right)-\left[I_{1}, I_{2}, \alpha_{2}, \beta_{2}\right] e^{-r T} N\left(d_{2}\right) \\
& =\left\{V_{1} e^{-\mu T} N\left(d_{1}\right)-I_{2} e^{-r T} N\left(d_{2}\right),\right. \\
& V_{2} e^{-\mu T} N\left(d_{1}\right)-I_{1} e^{-r T} N\left(d_{2}\right), \\
& \alpha_{1} e^{-\mu T} N\left(d_{1}\right)+\beta_{2} e^{-r T} N\left(d_{2}\right), \\
& \left.\beta_{1} e^{-\mu T} N\left(d_{1}\right)+\alpha_{2} e^{-r T} N\left(d_{2}\right)\right\}
\end{aligned}
$$

$\mathrm{V}$ and I are the different factors of the cost and benefit of enterprise information, in fact, are two matrices. Taking into account the versatility of the formula, we use the vector (V), E (I) mode in the modeling.

$$
\left\{\begin{aligned}
d_{1} & =\frac{\ln \frac{\|E(V)\|}{\|E(I)\|}+\left(r+\frac{\sigma^{2}}{2}\right) T}{\sigma \sqrt{T}} ; \\
d_{2} & =\frac{\ln \frac{\|E(V)\|}{\|E(I)\|}+\left(r-\frac{1}{2} \sigma^{2}\right) T}{\sigma \sqrt{T}} ; \\
V & =\left(V_{1}, V_{2}, \ldots, V_{n}\right) ; \text { For } V_{i}=\left[V_{i_{1}}, V_{i_{2}}, \alpha_{i_{1}}, \beta_{i_{1}}\right] \\
I & =\left(I_{1}, I_{2}, \ldots, I_{m}\right) ; \text { For } I_{j}=\left[I_{j_{1}}, I_{j_{2}}, \alpha_{j_{2}}, \beta_{j_{2}}\right]
\end{aligned}\right.
$$

\section{Empirical Analysis}

The data in this article is collected through questionnaires. The final valid sample is 103 , and has a reasonable distribution in the region and firm size. After double data dimensionless processing, the real option value can be calculated using MATLAB. The results can be expressed as the following figure. In the following figure, $M E I O V=\left[E I O V_{1}, E I O V_{2}, E I O V_{\alpha}, E I O V_{\beta}\right]$. 


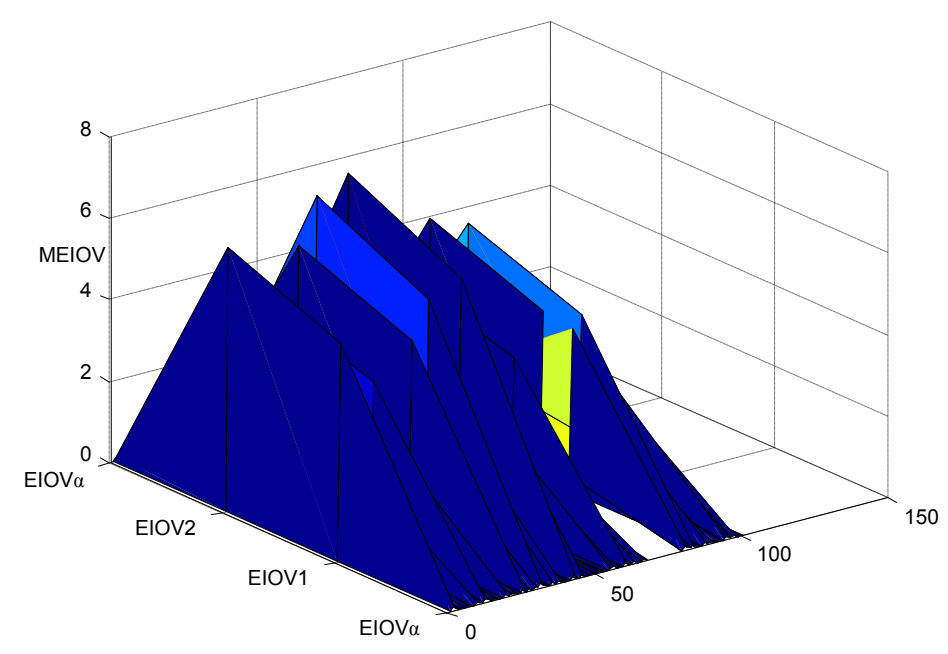

Fig.1 Option value of trapezoidal fuzzy number

Through past study, this paper summarized the key indicators of the low carbon information technology as the following factors: energy consumption per unit of output, utilization of green energy-saving equipment, the effective utilization of information technology equipment, suitable for low-carbon concept awareness and product of low-carbon.

$M E I O V=\left[E I O V_{1}, E_{2} V_{2}, E I O V_{\alpha}, E I O V_{\beta}\right]$.

Through MATLAB, the result can be shown as below.

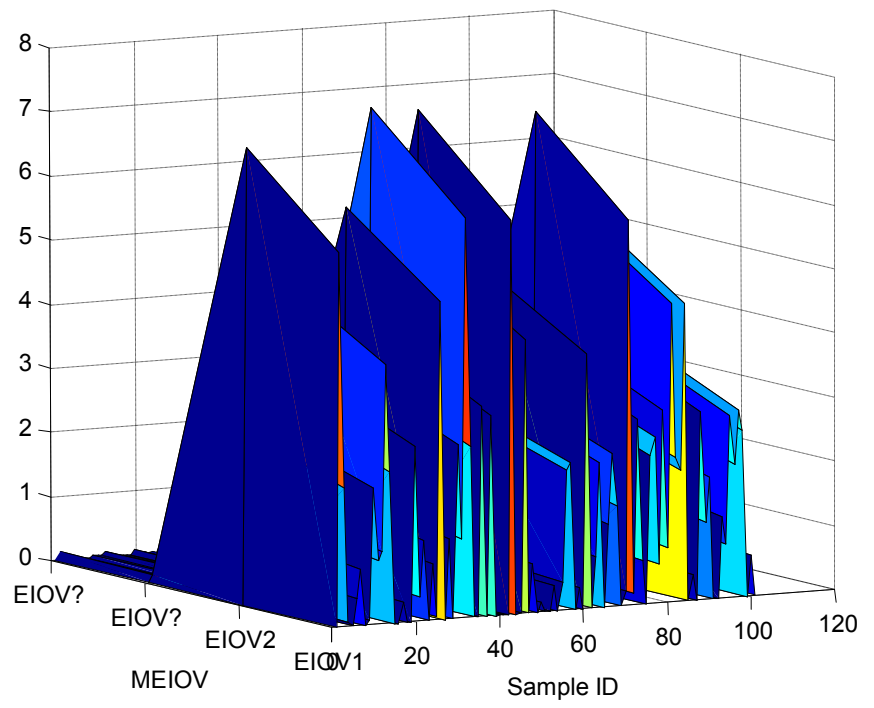

Fig.2 Option value with low-carbon index

\section{Conclusions and Prospect}

Through analysis of the model results, the following conclusions can be found: First, The higher the cost of information technology, the smaller the enterprise information value of real options. The higher the benefits of information technology, enterprise information value of real options. Second, in the case of the other parameters constant, the greater the volatility, the higher of information value of real options. This is one of the core concepts of real options. Volatility not only represents uncertainty and loss, but also gains. Third, the introduction of low-carbon factors, does not always reduce the 
value of real options of the information technology. Low-carbon indicators show that the potential and strength of the enterprises in the development of low carbon information may increase the enterprise value; And at the same time, low-carbon requirements, in a certain stage, can make the cost of business increase and reduce the value of the business. So, the low-carbon factors and the development of information technology do not exist simply linear relationship. Finally, it is not true that the higher level of information technology, the greater real option value of enterprise information. There is no absolute concept, but the concept of relative value.

This paper is an in-depth study of enterprise information value assessment with integrated using of fuzzy mathematics, finance, and multi-field theories and methods, and solves the following issues: This study gives a comprehensive, objective and quantifiable IT assessment model for the analysis of IT investment guided by the IT value, with the consideration of the uncertainty and volatility of the IT investment and the diversification and intangibility of the IT profit. The real option theory has been applied to the IT evaluation, and establishes a quantifiable model for the value assessment of the information technology. By studying the relationship and mutual influence pattern between IT and low-carbon index, this paper provides theoretical guidance for the low-carbon IT development.

However, due to limited time and ability, there are still many shortcomings and deficiencies in this paper. For example, the enterprise information value of real options is the relative value, not the absolute value, which means thi methods can be used to optimize other enterprise information assessment methods, but cannot replace them. Beside, the model did not consider the impact of the competitor's reaction, external technological innovation and other factors. This paper is based on EICMM theory, real options theory and the theory of fuzzy mathematics, builds the real options model under low-carbon concept, and makes some improvement in the evaluation of enterprise information construction. However, many problems, as referred above, need to be solved and optimized in the future work.

This article is based on the Beijing Philosophy and Social Sciences the 11th Five-Year Plan Project Based on low-carbon development ideas Beijing Information Evaluation Index System Study, whose number is [10BaJG384]; and on the Beijing Natural Science Foundation Project of Information properties of low-carbon economic development path and strategies study, whose number is [9123025]. This article is on the basis of existing research results, provide a new information technology valuation model framework, and finally give guidance for the construction of enterprise information under low-carbon idea.

\section{References}

[1] Paul M. Tuten. A Model for the Evaluation of IS/IT Investments[D], Nova Southeastern University, 2009

[2] Solow R, We'd better watch out [Z]. New York Times Book Review, 1987, 12:36

[3] Mckinsey, IT and productivity[R], 2001, 10, 17

[4] Moschella D C. Wave of power: Dynamics of Global Technology Leadership 1964-2010, [M]. New York:AMACOM, 1997

[5] Brian L.Information Technology investments:Characteristics, choices, market risk and value[J].Information Systems Frontiers，2003，（5）:289 301

[6] Lee B.An intergrated assessment of productivity and efficiency impacts of information technology investments, old data, new analysis and evidence[J].Journal of Producticity Analysis, 1999, (12): :21 43

[7] Olafssan S.Making decisions under uncertainty-implications for high technology investments[J].BT TechnologyJournal, 2003, (2) : 170 183 
[8] Karl Westerlind. Evaluating Return On Information Technology Investment, Gothenburg University[D], 2004

[9] Greenpeace International. Make It Green----Cloud Computing and its Contribution to Climate Change, March, 2010.

[10]Stern, N. etc. Stern Review: The Economics of Climate Change, HM Treasury, London, 2006.

[11]Microsoft. Information Technology: A Key to Strengthening Economies and Advancing National Priorities, 2010.

[12]Tapio P.Towards a theory of decoupling: degrees of decoupling in the EU and the case of road traffic in Finland between 1970 and 2001[J].Transport Policy, 2005, 12:137-151.

[13]Daniel Castro. Learning from the Korean Green IT Strategy, The Information Technology \& Innovation Foundation, August, 2009.

[14]Tiansheng Xu, Hong Qiao. Month Effect Research of SSE A-share Based on Balanced Influence. The 2nd IEEE International Conference on Information Management and Engineering Proceedings. 2010, 451 453 